\title{
Description, Kinetic and Equilibrium Studies of the Adsorption of Carbon Dioxide in Mesoporous Iron Oxide Nanospheres
}

\author{
Mohamed.G. El-Desouky 1,* ${ }^{(\mathbb{D})}$, A. Shahat ${ }^{2(\mathbb{D})}$, Ashraf.A. El-Bindary ${ }^{3(\mathbb{D})}$, Mohamed.A. El-Bindary 4 (i)

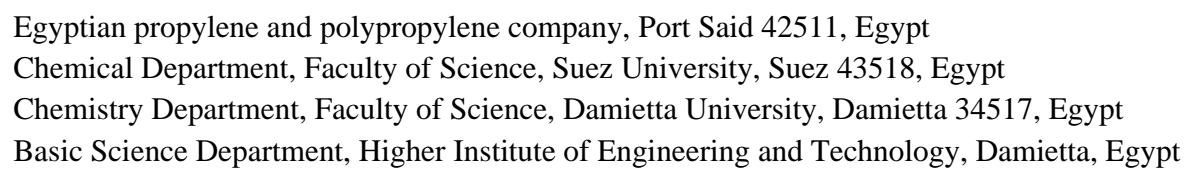

Received: 14.02.2021; Revised: 5.04.2021; Accepted: 8.04.2021; Published: 26.04.2021

\begin{abstract}
Mesoporous iron oxide nanospheres (MINs) have been successfully synthesized and have proven to be high-efficiency adsorbents. The morphology of the MINs is very uniform in spherical form, with an average particle size of 23-27 nm in the diameter range. MINs content has a fairly high BET surface area of $188.25 \mathrm{~m}^{2} \mathrm{~g}^{-1}$ and a total volume of $0.14 \mathrm{~cm}^{3} \mathrm{~g}^{-1}$ pores. Thus, seams were seen as potential $\mathrm{CO}_{2}$ sequestration reservoirs to reduce greenhouse gas emissions. The $\mathrm{CO}_{2}$ adsorption was favorable at low temperature and dry MINs conditions. However, MINs have a high adsorption capacity of $0.15 \mathrm{mmol} / \mathrm{g}$. The $\mathrm{CO}_{2}$ adsorption isotherm of all coal samples according to the IUPAC classification of adsorption isotherms fits category I, which most likely explains adsorption confined to a few layers of molecules (micropores and mesopores). The balancing assessment using Langmuir, Henry, Dubbin, Temkin, Toth, Harkins-Jura, Elovich, Redlich-Peterson, and Josene model provided the best fit for any experimental adsorption data that predict heterogeneous surface properties of MINs.
\end{abstract}

Keywords: MINs; isotherm models; $\mathrm{CO}_{2}$ adsorption.

(C) 2021 by the authors. This article is an open-access article distributed under the terms and conditions of the Creative Commons Attribution (CC BY) license (https://creativecommons.org/licenses/by/4.0/).

\section{Introduction}

The primary cause of global warming is the release of carbon dioxide $\left(\mathrm{CO}_{2}\right)$ gas into the atmosphere. $\mathrm{CO}_{2}$ is the main greenhouse gas emitted by the electricity, gas production, mining, chemical and petrochemical industries, iron and steel industries, and cement industries. The Scripps Institute of Oceanography has recently measured that the global average temperature rose by 0.6 to $1{ }^{\circ} \mathrm{C}$ as the $\mathrm{CO}_{2}$ concentration increased from $315 \mathrm{ppm}$ in March 1958 to 398 ppm in January 2014 [1,2]. The International Panel on Climate Change (IPCC) forecasts that the average $\mathrm{CO}_{2}$ concentration may rise to $570 \mathrm{ppm}$ by 2100 , causing the global average temperature and mean sea level to rise by approximately $1.9^{\circ} \mathrm{C}$ and $3.8 \mathrm{~m}$, respectively [3].

One of the essential features of porous materials is the surface area since it closely links to efficiency in many applications, such as gas storage, gas separation, and catalyzing. The most common method of determining the surface area and pore volume of porous materials, including microporous and mesoporous materials, is to analyze the isotherms based on nitrogen or argon adsorption Brunauer-Emmett-Teller (BET). The porous metal oxide formed by organic metallic atom-atom connectors from materials (or classes of metallic atoms) also 
attracts much interest in an arrangement with pores determined by the crystal structure, as shown by a large number of reviews they get.

In recent years, various metal oxides, such as ferrous oxides, manganese oxides, aluminum oxides, titanium oxides, magnesium oxides, and nanoparticles of cerium oxides, have been used as pollutant-removal adsorbers [4]. Many scientists are interested in iron-based materials due to their chemical stability, biocompatibility, amphoteric surface activity, improved catalytic activity, and dispensability [5]. The most stable iron oxide under ambient conditions (alpha- $\mathrm{Fe}_{2} \mathrm{O}_{3}$ ) is widely used to treat catalysts, pigments, sensors, gas purification, and water [6,7].

The metal oxide obtained from metal organic frame work(MOFs) has various features that make them an essential part of the mesoporous metal oxide derived from organic metal frameworks to explore sorbents. Pores in MOFs form an integral part of the material's crystal structure and have a regularity degree not seen in some other sorbents [8].

The adsorption of $\mathrm{CO}_{2}$ to MINs during sequestration and the desorption of $\mathrm{CO}_{2}$ from MINs by depressurization must therefore be understood. However, the deviation between Hysteresis is called adsorption and desorption of isothermal gas on porous materials. $[9,10]$. The adsorption of $\mathrm{CO}_{2}$ to MINs during sequestration and the mechanism for desorption of $\mathrm{CO} 2$ from MINs by depressurization is therefore important to understand. However, there is a deviation in working conditions such as pressure and temperature between adsorption and isothermal desorption of gases on mesoporous materials called Hysteresis [11,12]. For the long-range storage sequestration of $\mathrm{CO}_{2}$, the mechanism of $\mathrm{CO}_{2}$ sorption Hysteresis is beneficial. Numerous $\mathrm{CO}_{2}$ sorption research studies are currently underway on various coal specimens not only for the practical assessment of the potential of MINs bed gas but also to understand the fundamental mechanisms of gas adsorption and desorption[13].

The adsorption/desorption of $\mathrm{CO}_{2}$ under subcritical conditions on dry MINs was calculated in this analysis. It was performed at $273 \mathrm{~K}$ with isothermal $\mathrm{CO}_{2}$ adsorption and a pressure of up to 1 bar. Desorption has been done by depressurizing $\mathrm{CO}_{2}$ from 1 bar in the meantime. Finally, the adsorption isotherm models were used to match the equilibrium adsorption results [14].

\section{Materials and Methods}

\subsection{Chemicals.}

Here, the chemicals used are of pure grade in this analysis and used without purification. Without a further purification process, chemicals were used as they were collected. Ferrous sulfate (99\%, Tianjin Kemiou Chemical Reagent, China), 2methylimidazole (Hmim) (Sinopharm chemical reagent Co. Ltd., China), ammonium hydroxide solution (NH3, 25-28\%, Nanjing Chemical Reagent Co. Ltd., China), anhydrous ethanol solution (NH3, 25-28\%, China) (99.7 percent, Sinopharm chemical reagent Co. Ltd., China). The adsorbent was prepared previously, synthesized, and characterized [15].

\subsection{Characterization techniques.}

The devices and related models are illustrated in Table 1. 


\begin{tabular}{l|l} 
Type of analysis & \multicolumn{2}{l}{ Table 1. List of instruments. } \\
\hline X-ray diffraction (XRD) & Codels \\
\hline Transmission electron microscopy (TEM) & TEM, FEI Teanci G2 F20, USA \\
\hline FTIR spectra & Jasco -FTIR-4100 spectrophotometer \\
\hline UV-visible spectrophotometer & HACH LANGE DR5000 \\
\hline Brunauer-Emmett-Teller (BET & ASAP 2020 (Micrometrics, USA) \\
\hline scanning electron microscope (SEM) & JEOL-JSM-6510 LV \\
\hline pH metre & HANNA (model 211) \\
\hline Sorptomat instrument & ASAP 2010 (Micrometrics, USA) (Study $\mathrm{CO}_{2}$ adsorption and desorption)
\end{tabular}

\subsection{Preparation of adsorbent.}

Based on previously published studies, MINs [16] have been synthesized. In a typical synthesis, $1.89 \mathrm{~g}$ of ferrous sulfate was dissolved in $50 \mathrm{ml}$ of methanol; $2 \mathrm{~g}$ of Hmim was added in $50 \mathrm{ml}$ of methanol; afterward, ferrous sulfate solution and Hmim were mixed and stirred to complete the crystallization for 6 hours at room temperature. The sample was gathered by centrifugation. Then, and then dried at $60{ }^{\circ} \mathrm{C}$ overnight.

\section{Results and Discussion}

\subsection{Characterization of MINs.}

\subsubsection{X-ray diffraction (XRD) patterns.}

The XRD pattern of the as-prepared MINs was used to identify the crystalline phases and to estimate the crystalline sizes. Fig. 1 indicates several distinct peaks at $2 \theta$ intervals $=$ $21.7 ; 28.9 ; 30.85 ; 38.98 ; 45.92 ; 50.22 ; 53.42 ; 59.96 ; 60.44 ; 71.589$ and $75.8^{\circ}$ which correspond to the diffraction planes (012), (104), (110), (113), (024), (122), (214), (300), (1010) and (220), respectively. The observed diffraction peaks interact well in rhombohedral structure to crystallize $\alpha-\mathrm{Fe}_{2} \mathrm{O}_{3}$ (JCPDS card $\mathrm{N}^{\circ}$ 24-0072). The fact indicated that particular nanocrystals $\alpha-\mathrm{Fe}_{2} \mathrm{O}_{3}$ could grow preferentially rather than randomly $[17,18]$. The mean size of the ordered $\alpha-\mathrm{Fe}_{2} \mathrm{O}_{3}$ nanoparticles was measured at half maximum from the full width (FWHM) and the Debye-Sherrer formula according to the equation below (Eq. 1):

$$
\mathrm{D}=\frac{K \lambda}{\beta \cos \theta}
$$

where $\mathrm{K}$ is the Scherer constant $(0.89 \AA), \lambda$ is the $\mathrm{X}$-ray wavelength $(1.54 \AA), \beta$ is the line broadening at half the maximum intensity (FWHM) in radians, $\theta$ is the Bragg angle, and $\mathrm{B}$ is the maximum of the Bragg diffraction peak. Of this Debye-Sherrer equation, the mean size of the as-prepared MINs was about $28 \mathrm{~nm}[19]$.

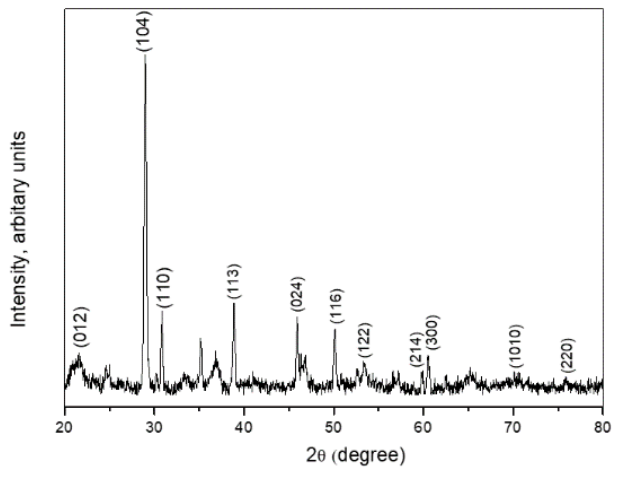

Figure 1. X-ray diffraction pattern of MINs. 


\subsubsection{Fourier-transform infrared (FTIR) spectroscopy.}

The functional groups present in MINs material were studied from the FT-IR in the range of 4000-400 $\mathrm{cm}^{-1}$. The FT-IR spectrum of MINs shows two bands at 2978 and 1622 $\mathrm{cm}^{-1}$ assigned to the H-O-H stretching modes and the bending vibration of the free or adsorbed water molecules. Also, the characteristic peak of Fe-O's stretching mode was detected at 621 $\mathrm{cm}^{-1}$, confirming the formation of $\alpha-\mathrm{Fe}_{2} \mathrm{O}_{3}[20]$.

\subsubsection{Brunauer-Emmett-Teller (BET) surface area.}

The adsorption isotherms of nitrogen at $77 \mathrm{~K}$ and the corresponding $\mathrm{BJH}$ pore size distribution curves of MINs are shown in Figure 3. The present MINs material reveals wellordered mesostructures. The $\mathrm{N}_{2}$ adsorption-desorption isotherms are usually of type IV according to the IUPAC classification with a well-developed "Knee" at low relative pressure that tends to become almost parallel to the pressure axis at high pressures, indicating an essentially microporous character with hysteresis loops [21]. Well-defined steps in the adsorption-desorption curves occur between the relative pressure, $\mathrm{P} / \mathrm{P}_{0}$, of $0.4-1.0$, suggesting the existence of a narrow distribution of mesopores [22]. This was supported by the existence of desorption hysteresis loop $\left(\mathrm{H}_{3} / \mathrm{H}_{4}\right.$ type), associated with slit-shaped pores, disclosing the simultaneous existence of micropores $(<2 \mathrm{~nm})$ and mesopores $(2-50 \mathrm{~nm})$ [23]. The content MINs have a relatively high BET surface area of $188.25 \mathrm{~m}^{2} \mathrm{~g}^{-1}$ and a total pore volume of 0.14 $\mathrm{cm}^{3} \mathrm{~g}^{-1}$. BJH's average pore size is $3.5 \mathrm{~nm}$, which is beneficial for adsorption application [24].

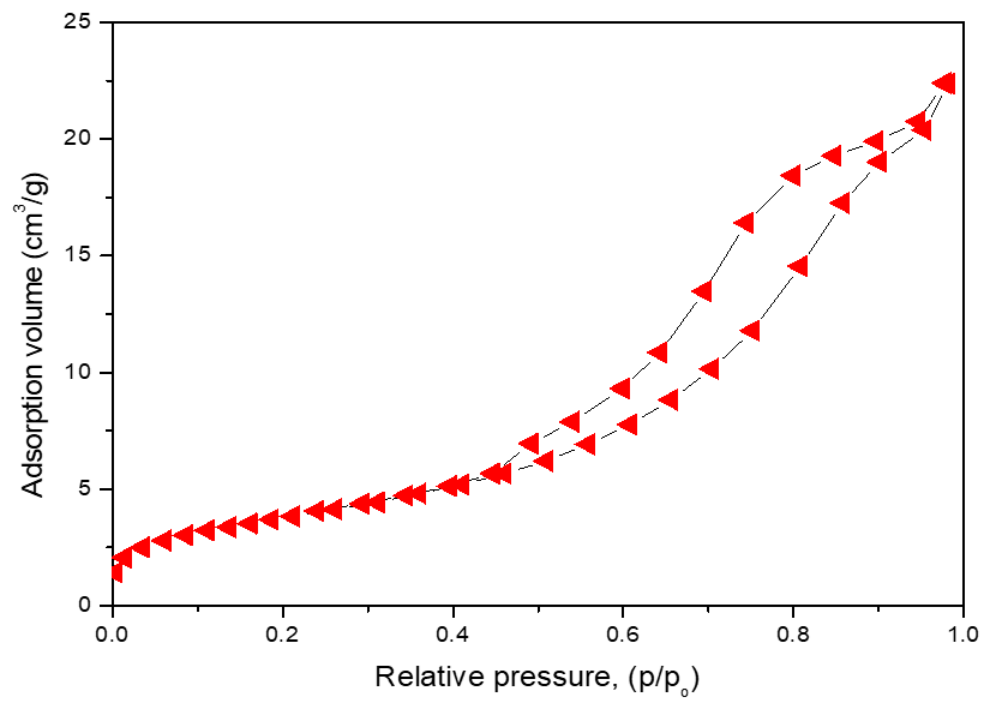

Figure 2. $\mathrm{N}_{2}$ adsorption-desorption isotherms for the MINs material at $77 \mathrm{~K}$.

\subsubsection{SEM and TEM analysis.}

The surface morphology of the iron oxide has been determined by scanning electron microscopy. The SEM image in Figure 3 indicates that the MINs materials are very uniform, spherical, and highly ordered mesostructures with an average diameter of $\sim 28 \mathrm{~nm}$ [25]. The high-resolution TEM image (Figure 4) also reveals that the frameworks of MINs materials are spherical and highly crystalline. The crystallite sizes are mainly in the range 23-27 nm, which coincides with the data from XRD patterns [26]. 


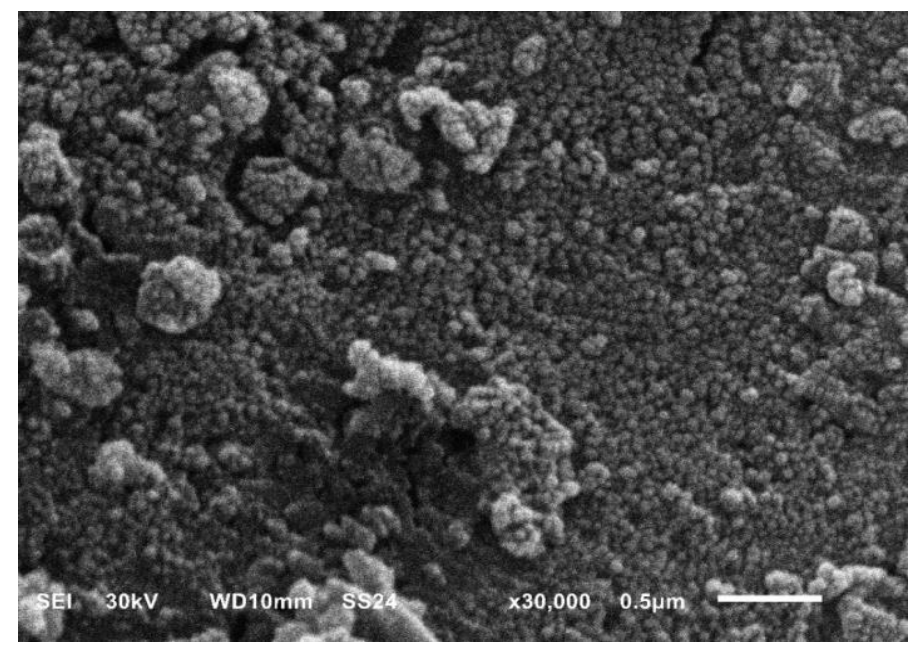

Figure 3. SEM image of MINs.

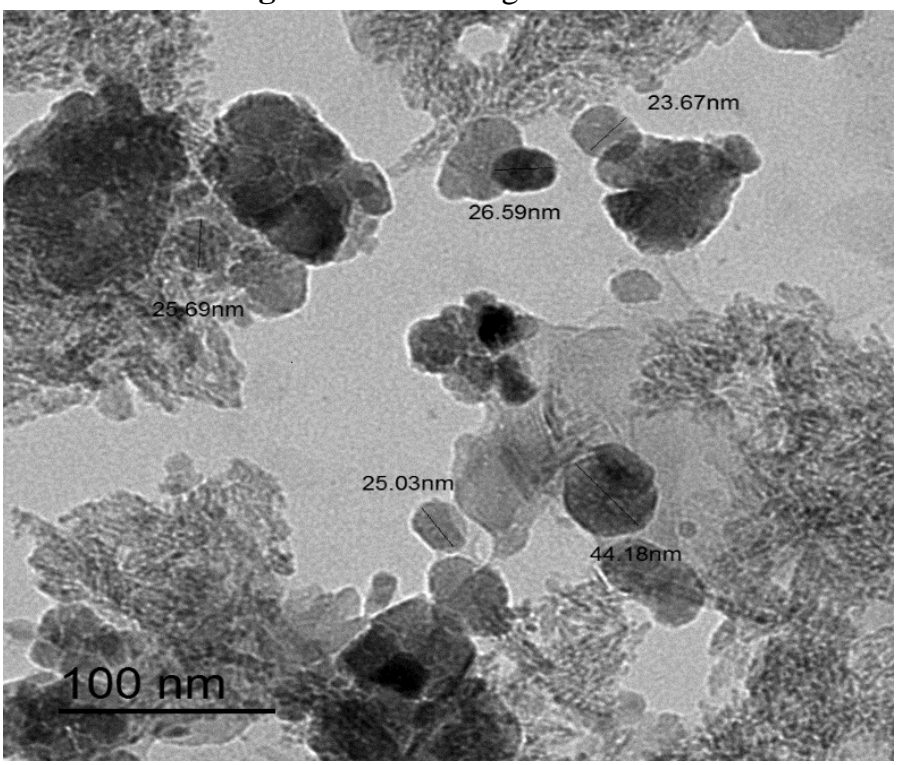

Figure 4. TEM image of MINs.

\subsection{Experimental procedure.}

Pressure-controlled before/after the release of the stored gas onto the manifold sample. The gas (reservoir) has been contained; the pressure begins to decrease as adsorption occurs. The gas law is used to measure the adsorbed $\mathrm{CO}_{2}$ by measuring the forces' changes while the temperature is kept constant. Inside the sample tubes, the adsorbed volume was eventually determined after minus the void volume. The temperature was raised to $90{ }^{\circ} \mathrm{C}$ for the first hour to remove moisture for 60 minutes $(1 \mathrm{hr})$. This follows a temperature increase of up to $150 \mathrm{oC}$ at $10 \mathrm{oC} / \mathrm{min}$ - the extraction of any sorbate species for 480 minutes from the samples (8 hours). The samples were ultimately subjected to $\mathrm{CO}_{2}$ gas adsorption using a bath temperature of $0{ }^{\circ} \mathrm{C}$ through a controlled circulating bath of water. Up to around $800 \mathrm{mmHg}$, the target pressure steadily increases at each target pressure point.

To measure the adsorption of $\mathrm{CO}_{2}$ to coal, it is essential to accurately measure the quantity of the measuring device using the state gas equation. Thus, the state equation determined the gas adsorption volume from the gas pressure change within the measuring device.

The adsorbed $\mathrm{CO}_{2}$ concentrations on MINs at temperature $273 \mathrm{~K}$ as pressure increased. Fig. 5 illustrates the experimental amounts of adsorbed $\mathrm{CO}_{2}$ on MINs at $273 \mathrm{~K}$. The sum of adsorbed $\mathrm{CO}_{2}$ on the sample of MINs is estimated at $273 \mathrm{~K}$. Since the MINs sample is 
heterogeneous and has a low specific surface area $\left(188.25 \mathrm{~m}^{2} / \mathrm{g}\right)$, it gives high adsorption on the MINs surface. According to the IUPAC classification, the shape isotherms of all $\mathrm{CO}_{2}$ adsorption on MINs follow Form IV reflecting mono-multilayer adsorption. Hysteresis loop type 3; at high pressure, as the pores have been filled, the slope shows increased adsorbate uptake. The inflection point usually occurs near the completion of the first monolayer and capillary condensation in the mesoporous. Desorption isotherms lie above isothermal adsorption. And the amount of $\mathrm{CO}_{2}$ adsorbed in the gas process, the isotherm of desorption was higher than the isotherm of adsorption isotherm of desorption at $273 \mathrm{~K}$, was obtained from depressurization after completion of adsorption experience. As illustrated in Figure 5, the adsorption of $\mathrm{CO}_{2}$ and the MINs desorption curves divergent degree of Hysteresis revealed [27]. $\mathrm{CO}_{2}$ adsorption and desorption isotherm tests of all samples of MINs describe a positive hysteresis between isothermic adsorption and desorption [28].

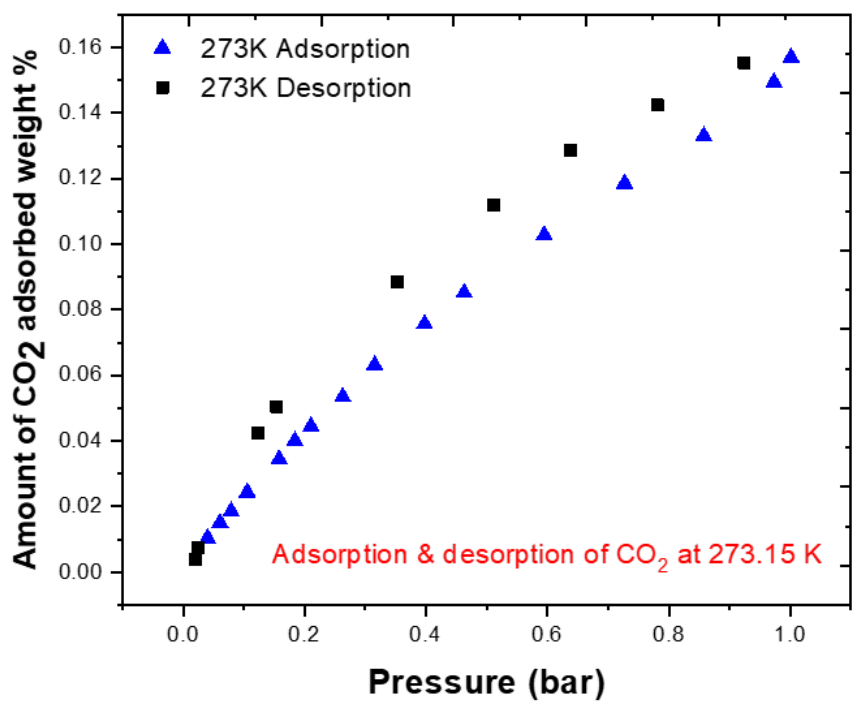

Figure 5. Adsorption and desorption of $\mathrm{CO}_{2}$ on MINs at $273.15 \mathrm{~K}$.

\subsubsection{Adsorption isotherms.}

The theoretical models of isothermal adsorption provide a substantial explanation of adsorption behavior. Such models demonstrate the interaction of the adsorbent with the adsorbent and explain the nature and mechanism. They describe how the adsorbent interacts with the adsorbent and clarify the nature and mechanism of gas adsorption in the adsorbent[29]. Equilibrium isothermal data from two and three-parameter models provide useful information on adsorption mechanisms and surface characteristics, and adsorbent affinity [30]. Therefore, it is crucial to verify the experimental equilibrium curves' correct correlation to optimize the conditions for designing adsorption systems. Langmuir, Henry, Dubbin, Temkin, Toth, HarkinJura, Elovich, Redlich Peterson, and Josene models were applied in this study to explore the adsorption behavior [31].

\subsubsection{Henry's isotherms.}

This is the simplest isothermic adsorption. The volume of surface adsorbent is proportional to the adsorptive gas partial pressure [32]. This isothermic model describes a suitable fit for adsorption at relatively low concentrations so that all adsorbed molecules are isolated from their nearest neighbors [33]. In this way, the balance adsorbs concentrations in the liquid and adsorbed phases are related to the linear expression in Figure 6 and Table 2. 


\subsubsection{Langmuir isotherms.}

Langmuir adsorption, which was primarily designed to describe adsorption in the gassolid phase, is also used to quantify and contrast the adsorption capacity of different adsorbents [34]. Langmuir isotherm accounts for the surface coverage by balancing adsorption and desorption (dynamic equilibrium) relative rates. [35]. The Langmuir equation can be written in linear form [36] (Figure 6 and Table 2).

\subsubsection{Freundlich isotherms.}

Isotherm is valid for processes of adsorption occurring on heterogonous surfaces [37]. This isotherm provides an expression that describes the surface's heterogeneity and the exponential distribution of the active sites and their energies [38]. Freundlich isotherm linear form is as follows [39] in Figure 6 and Table 2.

\subsubsection{Dubinin-Radushkevich isotherm.}

Dubinin-Radushkevich isotherm model [40] is an empirical adsorption model generally applied to express adsorption mechanisms with Gaussian distribution of energy on heterogeneous surfaces [41]. This isotherm is only appropriate for intermediate concentrations of adsorbents since it exhibits unrealistic asymptotic behavior and does not predict Henry's laws at low pressure [30]. The model is a semiempirical equation in which a pore-filling mechanism is accompanied by adsorption. It presumes a multilayer character involving Van Der Waal's forces, applicable to physical adsorption processes, and is a fundamental equation that describes the adsorption of microporous sorbents qualitatively by gasses and vapors [42] (Figure 6 and Table 2).

\subsubsection{Harkin-Jura isotherm.}

Harkin-Jura isotherm model assumes the possibility of multilayer adsorption on absorbents' surface having heterogeneous pore distribution [43] (Figure 6 and Table 2).

\subsubsection{Temkin isotherm.}

Temkin isotherm model considers the effects of indirect adsorbing/adsorbing interactions on the adsorption process; it is also assumed that the adsorption heat $\left(\mathrm{H}_{\mathrm{ads}}\right)$ of all layer molecules decreases linearly due to increased surface coverage [44] (Figure 6 and Table 2).

\subsubsection{Elovich isotherm.}

The equation that defines this model is based on a kinetic principle that assumes that adsorption sites increase exponentially with adsorption; this implies multilayer adsorption [45]. The equation was first developed to describe the kinetics of chemisorption of gas onto solids $[46,47]$ (Figure 6 and Table 2).

\subsubsection{Redlich-Peterson isotherm.}

The isotherm Redlich-Peterson is a mix of the Langmuir and Freundlich isotherms. The numerator is from the isothermic Langmuir and has the advantage of approaching the Henry region at infinite dilution [47-49] (Figure 6 and Table 2). 

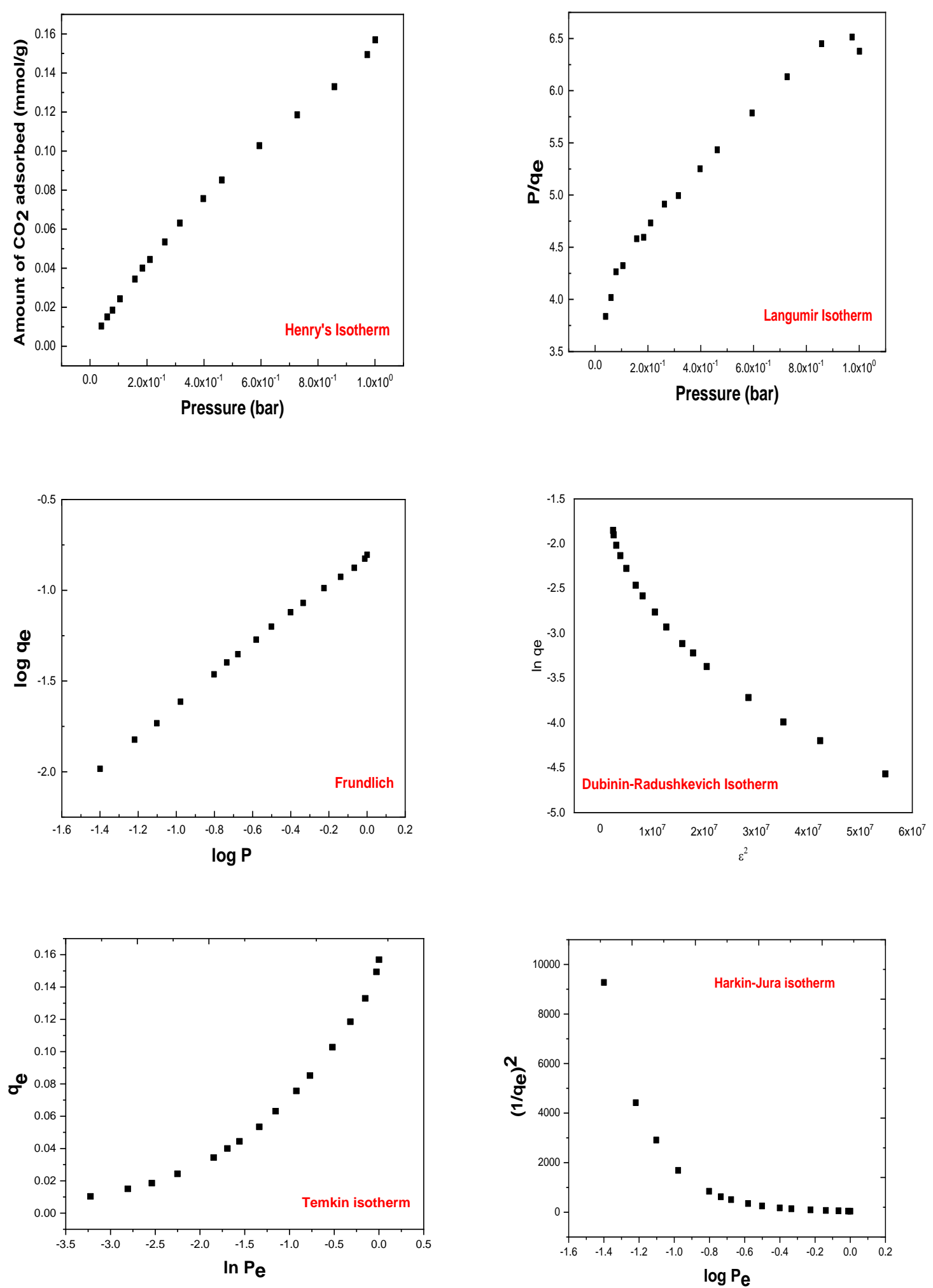

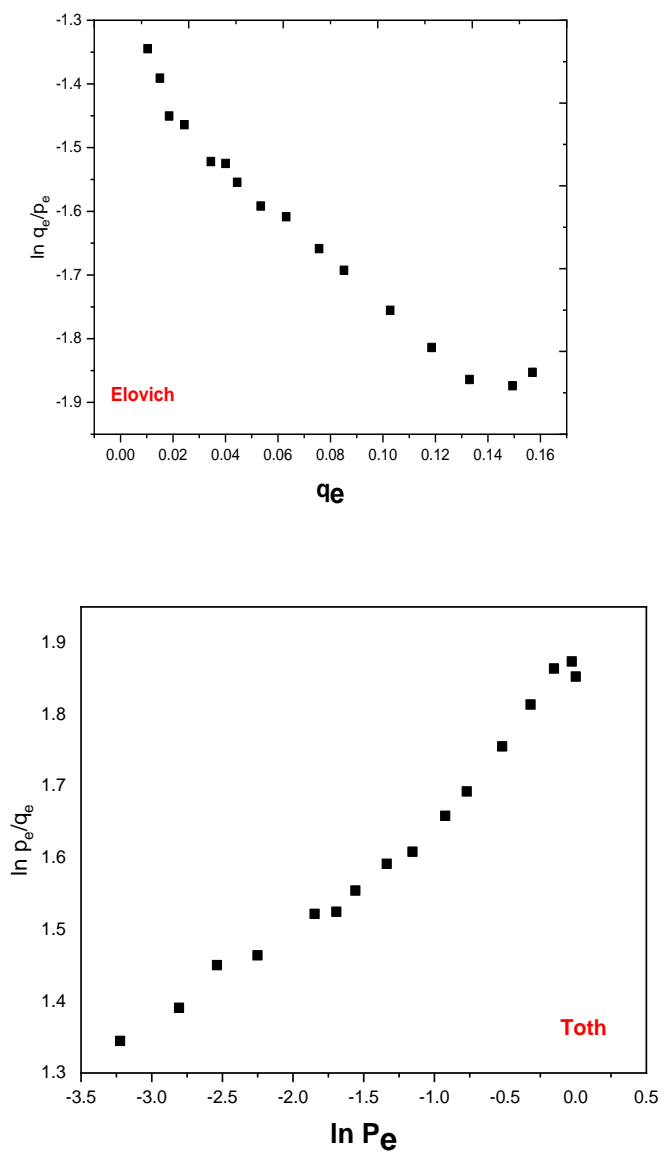
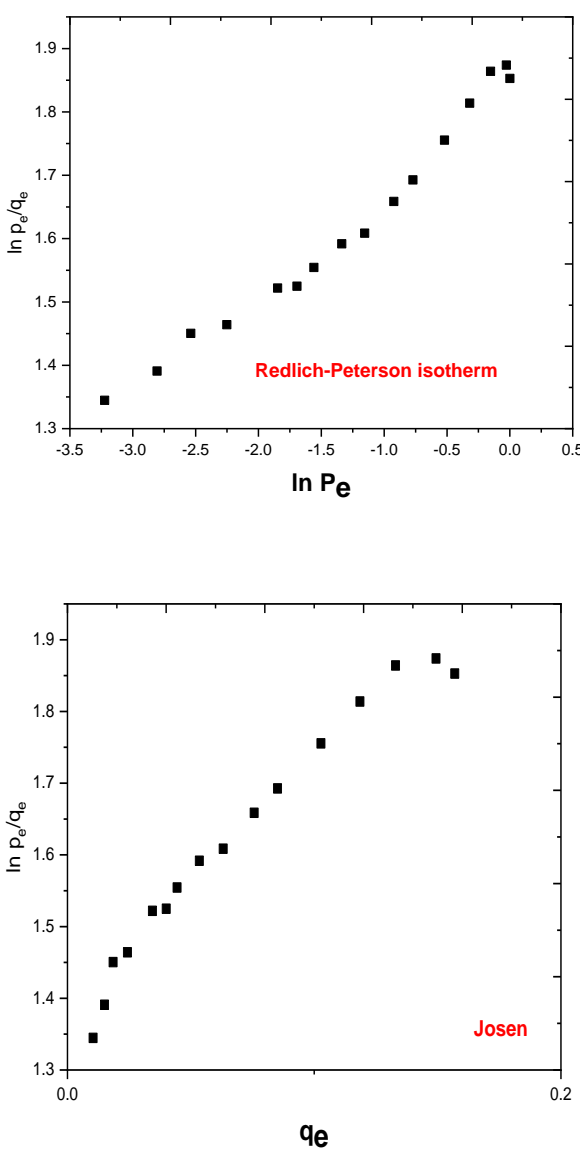

Figure 6. Adsorption isotherm models.

\subsubsection{Toth isotherm.}

The Toth isotherm is another empirical modification of the Langmuir equation aiming to reduce the error between experimental data and the predicted value of equilibrium data. This model is most useful in describing heterogeneous adsorption systems that satisfy both low and high-end boundary adsorbate concentrations [50]. This isothermic model has applied to model multiple multilayers and heterogeneous adsorption systems. This approved that the MINs have a heterogeneous surface, fitted to the Freundlich model (Figure 6 and Table 2).

\subsubsection{Jossen isotherm.}

The Jossens isotherm model predicts a simple equation based on the energy distribution of adsorbate-adsorbent interactions at adsorption sites [51]. This model assumes the adsorbent has a heterogeneous surface in terms of its interactions with the adsorbent $[52,53]$ ( Figure 6 and Table 2).

\subsubsection{Adsorption kinetics and mechanism studies.}

The $\mathrm{CO}_{2}$ adsorbed relation between time and quantity was illustrated in Figure 7. The adsorption rate decreased as the cycle's duration increases as it achieves equilibrium [54]. 
Table 2. Isotherms and their linear forms for the adsorption of $\mathrm{CO}_{2}$ onto MINs.

\begin{tabular}{|c|c|c|c|c|}
\hline Isotherm & \multicolumn{2}{|c|}{ Equation } & \multicolumn{2}{|c|}{ Value of parameters } \\
\hline \multirow{4}{*}{ Henry } & \multirow{4}{*}{$\mathrm{q}_{\mathrm{e}}=\mathrm{K}_{\mathrm{HE}} \mathrm{P}_{\mathrm{e}}$} & \multirow{4}{*}{$\begin{array}{l}\text { The constants } \mathrm{K}_{\mathrm{HE}} \text { are calculated by the plot of } \mathrm{q}_{\mathrm{e}} v s . \\
\qquad \mathrm{Pe}_{\mathrm{e}} \text { with slope } \mathrm{K}_{\mathrm{HE}}\end{array}$} & $\mathrm{q}_{\mathrm{m} \exp (\mathrm{mmol} / \mathrm{g})}$ & 0.15698 \\
\hline & & & $\mathrm{q}_{\mathrm{m}}(\mathrm{mmol} / \mathrm{g})$ & 0.14706 \\
\hline & & & KHE & 0.14706 \\
\hline & & & $\mathrm{R}^{2}$ & 0.9166 \\
\hline \multirow{4}{*}{ Langmuir } & \multirow{4}{*}{$\frac{\mathrm{p}_{\mathrm{e}}}{\mathrm{q}_{\mathrm{e}}}=\frac{1}{\mathrm{q}_{\mathrm{m}} \mathrm{K}_{\mathrm{L}}}+\frac{\mathrm{p}_{\mathrm{e}}}{\mathrm{q}_{\mathrm{m}}}$} & \multirow{4}{*}{$\mathrm{K}_{\mathrm{L}}$ and $\mathrm{q}_{\mathrm{m}}$ calculated from a linear plot of $\mathrm{p} / \mathrm{q}_{\mathrm{e}} v s \cdot \mathrm{p}_{\mathrm{e}}$} & $\mathrm{q}_{\mathrm{m}}(\mathrm{mmol} / \mathrm{g})$ & 0.149 \\
\hline & & & $\mathrm{K}_{\mathrm{L}}\left(\mathrm{bar}^{-1}\right)$ & 4.08 \\
\hline & & & $\mathrm{R}_{\mathrm{L}}$ & 0.86 \\
\hline & & & $\mathrm{R}^{2}$ & 0.96091 \\
\hline \multirow{4}{*}{ Freundlich } & \multirow{4}{*}{$\log q_{e}=\log K_{F}+\frac{1}{n} \log P_{e}$} & \multirow{4}{*}{$\begin{array}{l}\text { The slope of the plot of } \log \mathrm{P}_{\mathrm{e}} v s . \log \mathrm{q}_{\mathrm{e}} \text { gives } 1 / \mathrm{n} \text {, } \\
\text { and the intercept yields the adsorption capacity, } \mathrm{K}_{\mathrm{F}} \\
(\mathrm{mmol} / \mathrm{g})\end{array}$} & $\mathrm{q}_{\mathrm{m}}(\mathrm{mmol} / \mathrm{g})$ & 0.15 \\
\hline & & & $\mathrm{K}_{\mathrm{F}}$ & 0.15 \\
\hline & & & $1 / \mathrm{n}$ & 0.833 \\
\hline & & & $\mathrm{R}^{2}$ & 0.99871 \\
\hline \multirow{6}{*}{ Dubinin-Radushkevich } & \multirow{3}{*}{$\ln \mathrm{q}_{\mathrm{e}}=\ln \mathrm{Q}_{\mathrm{DR}}-\mathrm{K}_{\mathrm{DR}} \varepsilon^{2}$} & \multirow{6}{*}{$\begin{array}{l}\text { The slope of the plot of } \ln \mathrm{q}_{\mathrm{e}} v s . \varepsilon^{2} \text { gives } \mathrm{K}_{\mathrm{DR}} \\
\left(\mathrm{mol}^{2} / \mathrm{kJ}^{2}\right) \text {, and the intercept yields the adsorption } \\
\text { capacity, QDR (mmol/g) } \\
B \text { and } A \text { are Harkin-Jura constants that can be } \\
\text { obtained from plotting } 1 / q_{\mathrm{e}}{ }^{2} v s . \log \mathrm{P}_{\mathrm{e}}\end{array}$} & $Q_{D R}$ & 0.13 \\
\hline & & & $\mathrm{K}_{\mathrm{DR}}$ & 5.22 \\
\hline & & & $\mathrm{R}^{2}$ & 0.934 \\
\hline & \multirow{3}{*}{$\frac{1}{\mathrm{q}_{\mathrm{e}}^{2}}=\frac{\mathrm{B}}{\mathrm{A}}-\frac{1}{\mathrm{~A}} \log \mathrm{P}_{\mathrm{e}}$} & & $\mathrm{B}$ & -0.2691 \\
\hline & & & $\mathrm{A}$ & 0.00023 \\
\hline & & & $\mathrm{R}^{2}$ & 0.6029 \\
\hline Isotherm & & Equation & \multicolumn{2}{|c|}{ Value of parameters } \\
\hline \multirow{3}{*}{ Temkin } & \multirow{3}{*}{$\mathrm{q}_{\mathrm{e}}=\beta_{\mathrm{T}} \ln \mathrm{K}_{\mathrm{T}}+\beta_{\mathrm{T}} \ln \mathrm{P}_{\mathrm{e}}$} & \multirow{3}{*}{$\begin{array}{l}\text { The parameters } \beta_{\mathrm{T}} \text { and } \mathrm{K}_{\mathrm{T}} \text { are the Temkin constants } \\
\text { that can be determined by the plot of } \mathrm{q}_{\mathrm{e}} v s . \ln \mathrm{P}_{\mathrm{e}}\end{array}$} & $\beta_{\mathrm{T}}$ & 0.0457 \\
\hline & & & $\mathrm{K}_{\mathrm{T}}$ & 2.86 \\
\hline & & & $\mathrm{R}^{2}$ & 0.899 \\
\hline \multirow{3}{*}{ Elovich } & \multirow{3}{*}{$\ln \frac{\mathrm{q}_{\mathrm{e}}}{\mathrm{P}_{\mathrm{e}}}=\ln \mathrm{K}_{\mathrm{e}} \mathrm{q}_{\mathrm{m}^{-}} \frac{\mathrm{q}_{\mathrm{e}}}{\mathrm{q}_{\mathrm{m}}}$} & \multirow{3}{*}{$\begin{array}{l}\text { The slope of the plot of } \ln \mathrm{q}_{\mathrm{e}} / \mathrm{p}_{\mathrm{e}} v s . \mathrm{q}_{\mathrm{e}} \text { gives } \mathrm{K}_{\mathrm{e}} \text { and } \\
\text { the intercept yields the adsorption capacity, } \mathrm{q}_{\mathrm{m}} \\
\text { (mmol/g) }\end{array}$} & $\mathrm{q}_{\mathrm{m}}$ & 0.113 \\
\hline & & & $\mathrm{K}_{\mathrm{e}}$ & 31.8 \\
\hline & & & $\mathrm{R}^{2}$ & 0.96103 \\
\hline \multirow{4}{*}{ Redlich-Peterson } & \multirow{4}{*}{$\ln \frac{\mathrm{P}_{\mathrm{e}}}{\mathrm{q}_{\mathrm{e}}}=\beta \ln \mathrm{P}_{\mathrm{e}}-\ln \mathrm{A}$} & \multirow{4}{*}{$\begin{array}{l}\text { The parameters } \beta \text { and } \mathrm{A} \text { are the Redlich-Peterson } \\
\text { constants that can be determined by the plot of } \ln \\
\qquad \mathrm{p}_{\mathrm{e}} / \mathrm{q}_{\mathrm{e}} v s . \quad \ln \mathrm{P}_{\mathrm{e}}\end{array}$} & $\beta$ & 0.077 \\
\hline & & & $\mathrm{A}$ & 0.15 \\
\hline & & & $\mathrm{q}_{\mathrm{e}}(\mathrm{mmol} / \mathrm{g})$ & 0.46 \\
\hline & & & $\mathrm{R}^{2}$ & 0.986 \\
\hline \multirow{3}{*}{ Toth } & \multirow{3}{*}{$\ln \frac{\mathrm{q}_{\mathrm{e}}^{\mathrm{n}}}{\mathrm{q}_{\mathrm{m}}{ }^{\mathrm{n}}-\mathrm{q}_{\mathrm{e}}{ }^{\mathrm{n}}}=\mathrm{n} \ln \mathrm{K}_{\mathrm{L}}+\mathrm{n} \ln \mathrm{P}_{\mathrm{e}}$} & \multirow{3}{*}{$\begin{array}{l}\text { The constants } \mathrm{n} \text { and } \mathrm{K}_{\mathrm{L}} \text { are calculated by the plot of } \\
\ln \left(\mathrm{q}_{\mathrm{e}} / \mathrm{q}_{\mathrm{m}}-\mathrm{q}_{\mathrm{e}}\right) v s . \ln \mathrm{p}_{\mathrm{e}} \text { with slope } \mathrm{n} \text { and intercept } \mathrm{n} \ln \\
\mathrm{K}_{\mathrm{L}}\end{array}$} & $\mathrm{n}$ & 0.6719 \\
\hline & & & $\mathrm{K}_{\mathrm{L}}$ & 12 \\
\hline & & & $\mathrm{R}^{2}$ & 0.62953 \\
\hline \multirow{3}{*}{ Jossens } & $\mathrm{P}_{\mathrm{e}}$ & $\mathrm{H}$ and $\mathrm{F}$ can be calculated from a linear plot of $\ln$ & $\mathrm{H}$ & 0.25 \\
\hline & $\ln \frac{\mathrm{e}}{\mathrm{q}_{\mathrm{e}}}=-\ln \mathrm{H}+\mathrm{F} \mathrm{qe}_{\mathrm{p}}^{\mathrm{p}}$ & $\mathrm{p}_{\mathrm{e}} / \mathrm{q}_{\mathrm{e}} v s . \mathrm{q}_{\mathrm{e}}$ & $\mathrm{F}$ & 0.179 \\
\hline & & & $\mathrm{R}^{2}$ & 0.713 \\
\hline
\end{tabular}




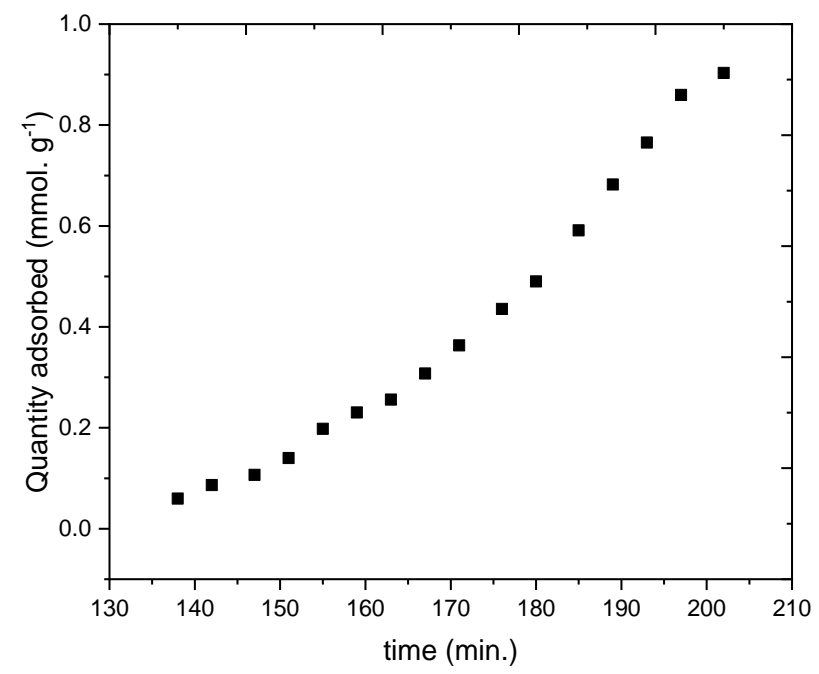

Figure 7. Adsorption of $\mathrm{CO}_{2}$ vs. time at $273 \mathrm{k}$.

The adsorption kinetics analysis defines the $\mathrm{CO}_{2}$ uptake rate, and this rate precisely regulates the $\mathrm{CO}_{2}$ uptake vs. time at the interface of the solid-gas phase. At first, the degree of elimination of measured $\mathrm{CO}_{2}$ by adsorption was high, then slowly slowed down until it reached an equilibrium above which the removal rate increased significantly. Its optimum adsorption was calculated at 202 minutes and is therefore known as the time of balance [55].

\subsubsection{The pseudo-first-order.}

The kinetic model equations underneath the pseudo-first-order kinetic models are used to match the experimental findings. And follow the adsorbing kinetics of tested MINs.

Pseudo-first - order formula by Lagergren [56,57].

$$
\log \left(q_{e}-q_{t}\right)=\log q_{e}-\left(\frac{K_{1}}{2.303}\right) t
$$

The $\ln \left(\mathrm{q}_{\mathrm{e}}-\mathrm{q}_{\mathrm{t}}\right) v s$. $\mathrm{t}$ plot gives a straight line with the $-K_{l}$ slope and intercept $\ln \mathrm{q}_{\mathrm{e}}$

\subsubsection{The pseudo-second-order.}

The experimental data related to a kinetic model of the pseudo-second-order. The kinetic model of the pseudo-second order[58,59].

$$
\frac{t}{q_{t}}=\frac{1}{K_{2} q_{e}^{2}}+\frac{\mathrm{t}}{\mathrm{q}_{\mathrm{e}}}
$$

The $K_{2}$ and $\mathrm{q}_{\mathrm{e}}$ values for the $\mathrm{CO}_{2}$ adsorbed amount determined from the slope and linear plot intercept of $\mathrm{t} / \mathrm{q}_{\mathrm{t}} v s$. $\mathrm{t}$.

\subsubsection{Webber (intraparticle diffusion).}

Weber assumed an empirical relationship with four parameters for a wide range of adsorption systems, which gave an excellent interpretation of the data pattern [60].

$$
q_{t}=K_{i} t^{1 / 2}+X
$$

The $\mathrm{K}_{\text {dif }}$ and $\mathrm{C}$ parameters were calculated from the $\mathrm{q}_{\mathrm{t}} v s . \mathrm{t}^{1 / 2}$ linear plot. 
Only the initial stages of adsorption (initial sharp rise) is necessary for the external resistance to mass transfer surrounding the particles. The second linear portion is the normal adsorption processes, with the regulation on intraparticle diffusion. If the plots do not pass through the origin, the pore diffusion is not the only rate-limiting step. Still, other kinetic models can also regulate the adsorption rate, all of which can function simultaneously $[61,62]$.

\subsubsection{Elovich.}

The equations which describe this model are based on a kinetic principle, which implies that adsorption sites increase exponentially with adsorption; this indicates multilayer adsorption [45].

$$
q_{t}=\frac{1}{\beta} \ln (\alpha \beta)+\frac{1}{\beta} \ln t
$$

The constants $\alpha$ and $\beta$ were obtained from a line plot $\mathrm{q}_{\mathrm{t}} v s$. In t on the slope and intercept.

The Elovich equation indicated that the adsorbent's active sites are heterogeneous and give different chemisorption activation energies. As the amount of $\mathrm{CO}_{2}$ increased, the constant $\alpha$ (attached to the rate of chemisorption) increased, and the constant $\beta$ (attached to the surface coverage) decreased [63].
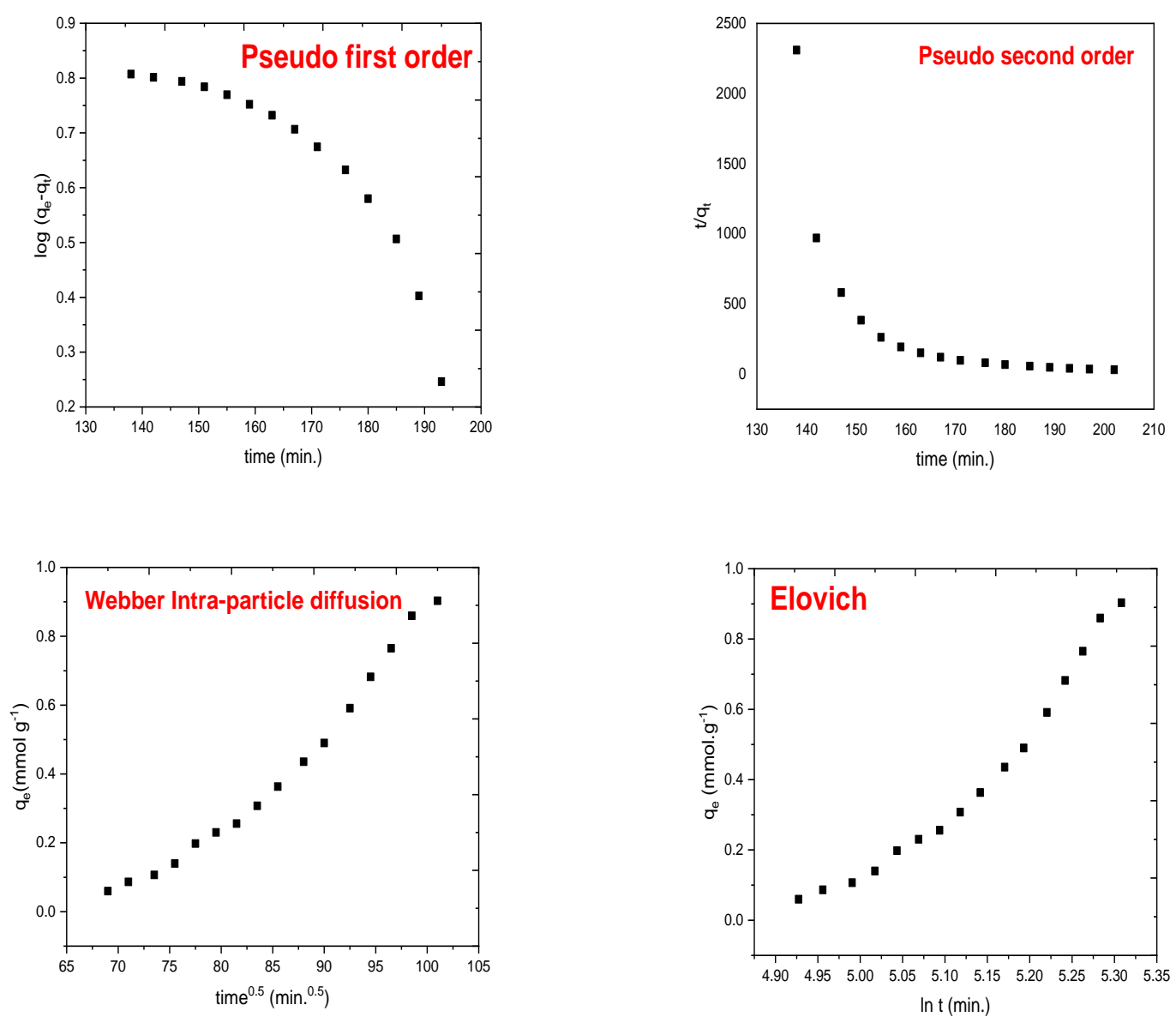

Figure 8. Results of applying the kinetic models to the data obtained from $\mathrm{CO}_{2}$ adsorption on the surface of MINs: Pseudo first order; Pseudo second-order; Webber Intra-particle diffusion and Elovich model.

If the experimental $\mathrm{CO}_{2}$ adsorption results are set at $273 \mathrm{k}$ and air pressure Kinetic models, values were obtained for their respective parameters, as shown in Table 2. 
Table 3. Kinetic models.

\begin{tabular}{l|l|l}
\multicolumn{1}{c}{ Models } & \multicolumn{1}{|c}{ Parameter } & \multicolumn{1}{c}{ MINs } \\
\hline \multirow{2}{*}{ Pseudo-First-order kinetic } & $K_{l}\left(\mathrm{~min}^{-1}\right)$ & 0.008 \\
\cline { 2 - 3 } & $\mathrm{R}^{2}$ & 0.8124 \\
\hline \multirow{2}{*}{ Pseudo-second-order kinetic } & $K_{2}\left(\mathrm{~g} \mathrm{mg}^{-1} \mathrm{~min}^{-1}\right)$ & 0.106 \\
\cline { 2 - 3 } & $\mathrm{R}^{2}$ & 0.438 \\
\hline \multirow{2}{*}{ Intraparticle diffusion } & $\mathrm{K}_{\mathrm{i}}\left(\mathrm{mgg}^{-1} \mathrm{~min}^{1 / 2}\right)$ & 0.0274 \\
\cline { 2 - 3 } & $\mathrm{X}_{\left(\mathrm{mgg}^{-1}\right)}$ & 1.923 \\
\cline { 2 - 3 } & $\mathrm{R}^{2}$ & 0.9629 \\
\hline \multirow{2}{*}{ Elovich } & $\beta\left(\mathrm{g} / \mathrm{mg}^{-1}\right)$ & 0.43 \\
\cline { 2 - 3 } & $\alpha\left(\mathrm{mgg}^{-1} \cdot \mathrm{min}^{-1}\right)$ & $1.22 \mathrm{E}-05$ \\
\cline { 2 - 3 } & $\mathrm{R}^{2}$ & 0.94
\end{tabular}

The order in which the kinetic models were fitted to the experimental data is as follows: intra-particle diffusion $>$ Elovich $>$ pseudo-first-order $>$ modified pseudo-first-order $>$ pseudosecond-order.

Applying the intraparticle diffusion model obtained the best fit for the experimental results.

It has been stated that the adsorption processes perform the following three main stages: external superficial adsorption, intraparticle diffusion, and the final balance. Figure 8 two linear stages due to the $\mathrm{CO}_{2}$ adsorption process in the aerogels, corresponding to the intraparticle diffusion and the equilibrium plateau, while external diffusion is absent. In principle, intraparticle diffusion is carried out in the mesopores; therefore, the adsorption rate was very high. The equilibrium plateau between $\mathrm{CO}_{2}$ and the MINs was reached, and the adsorption rate at this stage was slower.

The second-best fit to the experimental data was obtained by applying the Elovich model. Therefore, there was an energetic heterogeneity of the superficial adsorption sites. The other models studied had a smaller correlation coefficient. Hence, they do not explain the adsorption processes that occurred with the same reliability. However, it is essential to mention that the pseudo-second-order model presented the worst adjustment, confirming that chemisorption was not involved in this process, meaning that the interactions between the adsorbate and the adsorbent were physical.

The $\alpha$ and $\beta$ constants obtained by applying the Elovich model have units of $\left(\mathrm{mgg}^{-1} \cdot \mathrm{min}^{-}\right.$ $\left.{ }^{1}\right)$ and $(\mathrm{g} / \mathrm{mg})$, respectively. The values of $\alpha$ determine the initial adsorption speed. Their values were $1.22 \mathrm{E}-05 \mathrm{mgg}^{-1} \cdot \mathrm{min}^{-1}$ ) for the materials MINs indicating that the initial adsorption rate is related to the capacity of $\mathrm{CO}_{2}$ adsorption under these conditions.

The constant $\beta$ presents the smallest value in the material $0.43 \mathrm{~g} / \mathrm{mg}$; therefore, this material had the highest capacity for adsorption of $\mathrm{CO}_{2}$ because it had the highest volume of mesopores [64]. In another work, it has also been reported that pseudo-first-order or pseudosecond-order models have not been the best fit for data obtained from the kinetics of $\mathrm{CO}_{2}$ adsorption at the solids' surface.

\section{Conclusions}

Mesoporous iron oxide (MINs) sample was tested for $\mathrm{CO}_{2}$ adsorption/desorption at a temperature of $273 \mathrm{~K}$ and pressure up to 1 bar. The adsorption capacity of MINs was 0.15 $\mathrm{mmol} / \mathrm{g}$. According to the IUPAC classification of adsorption isotherms, the $\mathrm{CO}_{2}$ adsorption isotherm of MINs sample follows type IV, which most probably describes the adsorption limited to a few molecular layers (micropores and mesopores). The adsorption and desorption isotherm results demonstrate Hysteresis between adsorption and desorption isotherms for the 
MINs sample. According to hysteresis classifications, the Hysteresis during $\mathrm{CO}_{2}$ adsorption and desorption process for MINs sample type $\mathrm{H}_{3}$ describe pores' shape that slits. Freundlich adsorption isotherm models presented the best fit with experimental data. This indicates that the adsorption occurs at the heterogeneous surface as the adsorption sites have varied affinities. Stronger binding sites are occupied first, and the binding strength decreased with increasing degree of occupation by predicting that material exhibits heterogeneous surface properties. The intraparticle diffusion model presents the best fit to the experimental data. This model was used to analyze the rate of data from the experiments. Both the intraparticle diffusion and the equilibrium plateau models resulted in estimations that agreed with the experimental data. The kinetic study showed that the Elovich model presents the second-best fit to the obtained data so that on the surface of the materials, the energy distribution is presented during the $\mathrm{CO}_{2}$ adsorption process

\section{Funding}

This search no funding.

\section{Acknowledgment}

This research has no acknowledgment.

\section{Conflicts of Interest}

The authors declare that they have no known competing financial interests or personal relationships that could have influenced the work reported in this paper.

\section{References}

1. Lee, D.; Jin, Y.; Jung, N.; Lee, J.; Lee, J.; Jeong, Y.S.; Jeon, S. Gravimetric Analysis of the Adsorption and Desorption of $\mathrm{CO}_{2}$ on Amine-Functionalized Mesoporous Silica Mounted on a Microcantilever Array. Environ. Sci. Technol. 2011, 45, 5704-5709, https://doi.org/10.1021/es200680v.

2. Lee, S.-Y.; Park, S.-J. Determination of the optimal pore size for improved $\mathrm{CO}_{2}$ adsorption in activated carbon fibers. J. Colloid Interface Sci. 2013, 389, 230-235, https://doi.org/10.1016/j.jcis.2012.09.018.

3. Zhao, H.-Y.; Cao, Y.; Lineberry, Q.; Pan, W.-P. Evaluation of $\mathrm{CO} 2$ adsorption capacity of solid sorbents. J. Therm. Anal. Calorim. 2011, 106, 199, https://doi.org/10.1007/s10973-011-1481-1.

4. El-Katori, E.E.; Ahmed, M.; El-Bindary, A.; Oraby, A.M. Impact of $\mathrm{CdS} / \mathrm{SnO}_{2}$ heterostructured nanoparticle as visible light active photocatalyst for the removal methylene blue dye. Journal of

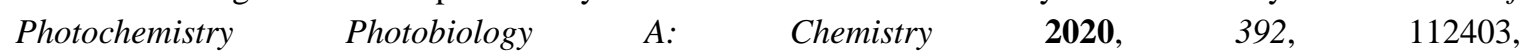
http://doi.org/10.1016/j.jphotochem.2020.112403.

5. Du, X.; Cheng, Y.; Liu, Z.; Hou, Z.; Wu, T.; Lei, R.; Shu, C. Study on the adsorption of $\mathrm{CH}_{4}, \mathrm{CO}_{2}$ and various $\mathrm{CH}_{4} / \mathrm{CO}_{2}$ mixture gases on shale. Alexandria Engineering Journal 2020, 59, 5165-5178, https://doi.org/10.1016/j.aej.2020.09.046.

6. Zhan, S.; Chen, D.; Jiao, X.; Liu, S. Facile fabrication of long $\alpha-\mathrm{Fe}_{2} \mathrm{O}_{3}, \alpha-\mathrm{Fe}$ and $\gamma-\mathrm{Fe}_{2} \mathrm{O}_{3}$ hollow fibers using sol-gel combined co-electrospinning technology. J. Colloid Interface Sci. 2007, 308, 265-270, https://doi.org/10.1016/j.jcis.2006.12.026.

7. Nalbandian, M.J.; Zhang, M.; Sanchez, J.; Choa, Y.-H.; Nam, J.; Cwiertny, D.M.; Myung, N.V. Synthesis and optimization of $\mathrm{Fe}_{2} \mathrm{O}_{3}$ nanofibers for chromate adsorption from contaminated water sources. Chemosphere 2016, 144, 975-981, https://doi.org/10.1016/j.chemosphere.2015.08.056.

8. Russell, B.A.; Migone, A.D. Low temperature adsorption study of $\mathrm{CO}_{2}$ in ZIF-8. Microporous Mesoporous Mater. 2017, 246, 178-185, https://doi.org/10.1016/j.micromeso.2017.03.030.

9. Abunowara, M.; Bustam, M.A.; Sufian, S.; Eldemerdash, U. Description of Carbon Dioxide Adsorption and Desorption onto Malaysian Coals under Subcritical Condition. Procedia Engineering 2016, 148, 600-608, https://doi.org/10.1016/j.proeng.2016.06.521. 
10. Ozdemir, E. Modeling of coal bed methane (CBM) production and $\mathrm{CO}_{2}$ sequestration in coal seams. International Journal of Coal Geology 2009, 77, 145-152, https://doi.org/10.1016/j.coal.2008.09.003.

11. He, J.; Shi, Y.; Ahn, S.; Kang, J.W.; Lee, C.-H. Adsorption and Desorption of $\mathrm{CO}_{2}$ on Korean Coal under Subcritical to Supercritical Conditions. The Journal of Physical Chemistry B 2010, 114, 4854-4861, https://doi.org/10.1021/jp911712m.

12. Mazzotti, M.; Pini, R.; Storti, G. Enhanced coalbed methane recovery. The Journal of Supercritical Fluids 2009, 47, 619-627, https://doi.org/10.1016/j.supflu.2008.08.013.

13. Du, X.; Guang, W.; Cheng, Y.; Hou, Z.; Liu, Z.; Yin, H.; Huo, L.; Lei, R.; Shu, C. Thermodynamics analysis of the adsorption of $\mathrm{CH}_{4}$ and $\mathrm{CO}_{2}$ on montmorillonite. Applied Clay Science 2020, 192, 105631, https://doi.org/10.1016/j.clay.2020.105631.

14. Huang, C.-L.; Wang, P.-Y.; Li, Y.-Y. Fabrication of electrospun $\mathrm{CO}_{2}$ adsorption membrane for zinc-air battery application. Chem. Eng. J. 2020, 395, 125031, https://doi.org/10.1016/j.cej.2020.125031.

15. Hassan, N.; Shahat, A.; El-Didamony, A.; El-Desouky, M.G.; El-Bindary, A.A. Mesoporous iron oxide nano spheres for capturing organic dyes from water sources. J. Mol. Struct. 2020, 1217, 128361, https://doi.org/10.1016/j.molstruc.2020.128361.

16. Ke, F.; Yuan, Y.-P.; Qiu, L.-G.; Shen, Y.-H.; Xie, A.-J.; Zhu, J.-F.; Tian, X.-Y.; Zhang, L.-D. Facile fabrication of magnetic metal-organic framework nanocomposites for potential targeted drug delivery. $J$. Mater. Chem. 2011, 21, 3843-3848, https://doi.org/10.1039/C0JM01770A.

17. Lassoued, A.; Lassoued, M.S.; Dkhil, B.; Ammar, S.; Gadri, A. Synthesis, photoluminescence and Magnetic properties of iron oxide $\left(\alpha-\mathrm{Fe}_{2} \mathrm{O}_{3}\right)$ nanoparticles through precipitation or hydrothermal methods. Physica E: Low-dimensional Systems and Nanostructures $\mathbf{2 0 1 8 ,}$ 101, 212-219, https://doi.org/10.1016/j.physe.2018.04.009.

18. Bhagavathi Pushpa, T.; Vijayaraghavan, J.; Sardhar Basha, S.J.; Sekaran, V.; Vijayaraghavan, K.; Jegan, J. Investigation on removal of malachite green using EM based compost as adsorbent. Ecotoxicol. Environ. Saf. 2015, 118, 177-182,https://doi.org/10.1016/j.ecoenv.2015.04.033.

19. Du, X.; Cheng, Y.; Liu, Z.; Yin, H.; Wu, T.; Huo, L.; Shu, C. $\mathrm{CO}_{2}$ and $\mathrm{CH}_{4}$ adsorption on different rank coals: A thermodynamics study of surface potential, Gibbs free energy change and entropy loss. Fuel 2021, 283, 118886,https://doi.org/10.1016/j.fuel.2020.118886.

20. Petrovic, B.; Gorbounov, M.; Masoudi Soltani, S. Influence of surface modification on selective $\mathrm{CO}_{2}$ adsorption: A technical review on mechanisms and methods. Microporous Mesoporous Mater. 2021, 312 , 110751,https://doi.org/10.1016/j.micromeso.2020.110751.

21. Hassan, N.; Shahat, A.; El-Didamony, A.; El-Desouky, M.; El-Bindary, A. Equilibrium, Kinetic and Thermodynamic studies of adsorption of cationic dyes from aqueous solution using ZIF-8. J. Moroccan Journal of Chemistry 2020, 8, 8-3 (2020) 2627-2637. https://doi.org/10.48317/IMIST.PRSM/morjchemv8i3.21127.

22. Wedler, C.; Span, R. A pore-structure dependent kinetic adsorption model for consideration in char conversion - Adsorption kinetics of $\mathrm{CO}_{2}$ on biomass chars. Chem. Eng. Sci. 2021, 231, 116281, https://doi.org/10.1016/j.ces.2020.116281.

23. Lai, L.S.; Yeong, Y.F.; Ani, N.C.; Lau, K.K.; Shariff, A.M. Effect of Synthesis Parameters on the Formation of Zeolitic Imidazolate Framework 8 (ZIF-8) Nanoparticles for $\mathrm{CO}_{2}$ Adsorption. Particulate Science and Technology 2014, 32, 520-528, https://doi.org/10.1080/02726351.2014.920445.

24. Chen, B.; Deng, S.; Zhao, L.; Li, S.; Wu, K.; Chen, L.; Zhao, J.; Yuan, X.; Liang, Y. Performance analysis of solar-assisted $\mathrm{CO}_{2}$ adsorption capture system based on dynamic simulation. Solar Energy 2020, 209, 628645, https://doi.org/10.1016/j.solener.2020.09.017.

25. Wang, B.; Kong, Q.; Quan, F.; Ji, Q.; Xia, Y. Preparation of nanostructured porous carbon composite fibers from ferrum alginate fibers. J. Appl. Polym. Sci. 2013, 128, 2216-2223, https://doi.org/10.1002/app.37679.

26. Namasivayam, C.; Kavitha, D. Removal of Congo Red from Water by Adsorption onto Activated Carbon Prepared from Coir Pith, an Agricultural Solid Waste. Dyes and Pigments 2002, 54, 47-58, https://doi.org/10.1016/S0143-7208(02)00025-6.

27. Busch, A.; Gensterblum, Y.; Krooss, B. Methane and $\mathrm{CO}_{2}$ sorption and desorption measurements on dry Argonne premium coals: Pure components and mixtures. International Journal of Coal Geology 2003, 55, 205-224,https://doi.org/10.1016/S0166-5162(03)00113-7.

28. Sang, Y.; Cao, Y.; Wang, L.; Yan, W.; Chen, T.; Huang, J.; Liu, Y.-N. N-rich porous organic polymers based on Schiff base reaction for $\mathrm{CO}_{2}$ capture and mercury(II) adsorption. J. Colloid Interface Sci. 2021, 587, 121130,https://doi.org/10.1016/j.jcis.2020.12.002. 
29. Davarpanah, E.; Armandi, M.; Hernández, S.; Fino, D.; Arletti, R.; Bensaid, S.; Piumetti, M. CO 2 capture on natural zeolite clinoptilolite: Effect of temperature and role of the adsorption sites. J. Environ. Manage. 2020, 275, 111229,https://doi.org/10.1016/j.jenvman.2020.111229.

30. Santhi, T.; Manonmani, S.; Smitha, T. Removal of methyl red from aqueous solution by activated carbon prepared from the Annona squmosa seed by adsorption. Chemical engineering research bulletin 2010, 14, 11-18,https://doi.org/10.3329/cerb.v14i1.3767.

31. Jung, W.; Lee, K.S. Isotherm and kinetics modeling of simultaneous $\mathrm{CO}_{2}$ and $\mathrm{H}_{2} \mathrm{O}$ adsorption on an aminefunctionalized solid sorbent. Journal of Natural Gas Science and Engineering 2020, 84, 103489,https://doi.org/10.1016/j.jngse.2020.103489.

32. Ruthven, D.M. Principles of adsorption and adsorption processes; John Wiley \& Sons: 1984.

33. Ayawei, N.; Ebelegi, A.N.; Wankasi, D. Modelling and Interpretation of Adsorption Isotherms. Journal of Chemistry 2017, 2017, 3039817,https://doi.org/10.1155/2017/3039817.

34. Kiwaan, H.; Atwee, T.; Azab, E.; El-Bindary, A. Photocatalytic degradation of organic dyes in the presence of nanostructured titanium dioxide. Journal of Molecular Structure 2020, 1200, 127115,https://doi.org/10.1016/j.molstruc.2019.127115 .

35. El-Bindary, A.A.; Toson, E.A.; Shoueir, K.R.; Aljohani, H.A.; Abo-Ser, M.M. Metal-organic frameworks as efficient materials for drug delivery: Synthesis, characterization, antioxidant, anticancer, antibacterial and molecular docking investigation. $J$ Applied Organometallic Chemistry 2020, 34, e5905.https://doi.org/10.1002/aoc.5905.

36. Dąbrowski, A. Adsorption-from theory to practice. Adv. Colloid Interface Sci. 2001, 93, 135-224, https://doi.org/10.1016/s0001-8686(00)00082-8.

37. Ayawei, N.; Ekubo, A.T.; Wankasi, D.; Dikio, E.D. Adsorption of congo red by Ni/Al- $\mathrm{CO}_{3}$ : equilibrium, thermodynamic and kinetic studies. Oriental Journal of Chemistry 2015, 31, 1307-1318, https://doi.org/10.13005/ojc/310307.

38. Boparai, H.K.; Joseph, M.; O'Carroll, D.M. Kinetics and thermodynamics of cadmium ion removal by adsorption onto nano zerovalent iron particles. J. Hazard. Mater. 2011, 186, 458-465, https://doi.org/10.1016/j.jhazmat.2010.11.029.

39. Ayawei, N.; Angaye, S.S.; Wankasi, D.; Dikio, E.D. Synthesis, characterization and application of Mg/Al layered double hydroxide for the degradation of congo red in aqueous solution. Open Journal of Physical Chemistry 2015, 5, 56.https://doi: 10.4236/ojpc.2015.53007

40. Travis, C.C.; Etnier, E.L. A Survey of Sorption Relationships for Reactive Solutes in Soil. J. Environ. Qual. 1981, 10, 8-17, https://doi.org/10.2134/jeq1981.00472425001000010002x.

41. El-Bindary, A.; El-Marsafy, S.; El-Maddah, A. Enhancement of the photocatalytic activity of ZnO nanoparticles by silver doping for the degradation of AY99 contaminants. Journal of Molecular Structure 2019, 1191, 76-84.https://doi.org/10.1016/j.molstruc.2019.04.064 .

42. Vo, T.K.; Nguyen, V.C.; Quang, D.T.; Park, B.J.; Kim, J. Formation of structural defects within UiO-66(Zr)$(\mathrm{OH})_{2}$ framework for enhanced $\mathrm{CO}_{2}$ adsorption using a microwave-assisted continuous-flow tubular reactor. Microporous Mesoporous Mater. 2021, 312, 110746, https://doi.org/10.1016/j.micromeso.2020.110746.

43. Foo, K.Y.; Hameed, B.H. Insights into the modeling of adsorption isotherm systems. Chem. Eng. J. 2010, 156, 2-10,https://doi.org/10.1016/j.cej.2009.09.013.

44. Kiwaan, H.A.; Atwee, T.M.; Azab, E.A.; El-Bindary, A.A. Efficient photocatalytic degradation of Acid Red 57 using synthesized $\mathrm{ZnO}$ nanowires. Journal of the Chinese Chemical Society 2019, 66, 89-98.https://doi.org/10.1002/jccs.201800092 .

45. Gubernak, M.; Kaczmarski, K.; Pola, W. Analysis of amylbenzene adsorption equilibria on an RP-18e chromatographic column. Acta Chromatographica 2003, 13. http://dx.doi.org/10.17344/acsi.2017.4105

46. Hassan, N.; El-Sonbati, A.; El-Desouky, M. Synthesis, characterization, molecular docking and DNA binding studies of Cu (II), Ni (II), Zn (II) and Mn (II) complexes. Journal of Molecular Liquids, 2017, 242, 293-307, https://doi.org/10.1016/j.molliq.2017.07.019.

47. Achmad, A.; Kassim, J.; Suan, T.K.; Amat, R.C.; Seey, T.L. Equilibrium, kinetic and thermodynamic studies on the adsorption of direct dye onto a novel green adsorbent developed from Uncaria gambir extract. Journal of Physical Science 2012, 23, 1-13. https://doi.org/10.1155/2017/3039817

48. Brouers, F.; Al-Musawi, T.J. On the optimal use of isotherm models for the characterization of biosorption of lead onto algae. J. Mol. Liq. 2015, 212, 46-51, https://doi.org/10.1016/j.molliq.2015.08.054. 
49. Chan, L.S.; Cheung, W.H.; Allen, S.J.; McKay, G. Error Analysis of Adsorption Isotherm Models for Acid Dyes onto Bamboo Derived Activated Carbon. Chin. J. Chem. Eng. 2012, 20, 535-542, https://doi.org/10.1016/S1004-9541(11)60216-4.

50. Jafari Behbahani, T.; Behbahani, Z. A new study on asphaltene adsorption in porous media. Petroleum and Coal 2014, 56, 459-466. https://doi.org/10.1021/ef3017255

51. Dilekoglu, M.F. Use of Genetic Algorithm Optimization Technique in the Adsorption of Phenol on Banana and Grapefruit Peels. J. Chem. Soc. Pak. 2016, 38. https://doi.org/10.1007/s13201-020-01213-3

52. Kumar, A.; Ropital, F.; de Bruin, T.; Diawara, B. Effects of surface orientations of Cr2O3 on CO2 adsorption: A DFT approach. Appl. Surf. Sci. 2020, 529, 147127, https://doi.org/10.1016/j.apsusc.2020.147127.

53. Bemani, A.; Baghban, A.; Mohammadi, A.H.; Andersen, P.Ø. Estimation of adsorption capacity of $\mathrm{CO}_{2}, \mathrm{CH}_{4}$, and their binary mixtures in Quidam shale using LSSVM: Application in $\mathrm{CO}_{2}$ enhanced shale gas recovery and $\mathrm{CO}_{2}$ storage. Journal of Natural Gas Science and Engineering 2020, 76, 103204, https://doi.org/10.1016/j.jngse.2020.103204.

54. Papa, E.; Landi, E.; Natali Murri, A.; Miccio, F.; Vaccari, A.; Medri, V. $\mathrm{CO}_{2}$ adsorption at intermediate and low temperature by geopolymer-hydrotalcite composites. Open Ceramics 2021, 5, 100048, https://doi.org/10.1016/j.oceram.2020.100048.

55. Lei, G.; Li, Q.; Liu, H.; Zhang, Y. Selective adsorption of $\mathrm{CO}_{2}$ by Hex-star phosphorene from natural gas: Combining molecular simulation and real adsorbed solution theory. Chem. Eng. Sci. 2021, 231, 116283, https://doi.org/10.1016/j.ces.2020.116283.

56. Ho, Y.S.; McKay, G. Sorption of dye from aqueous solution by peat. Chem. Eng. J. 1998, 70, 115-124, https://doi.org/10.1016/S0923-0467(98)00076-1.

57. Lagergren, S.K. About the theory of so-called adsorption of soluble substances. Sven. Vetenskapsakad. Handingarl 1898, 24, 1-39.https:// doi. :10.1016/j.bej.2005.01.020

58. Taran, M.; Safaei, M.; Karimi, N.; Almasi, A. Benefits and Application of Nanotechnology in Environmental Science: an Overview. Biointerface Research in Applied Chemistry 2021, 11, 7860-7870, https://doi.org/10.33263/BRIAC111.78607870.

59. Mohamed, G.; Hassan, N.; Shahat, A.; El-Didamony, A.; Ashraf, A. Synthesis and Characterization of Porous Magnetite Nanosphere Iron Oxide as a Novel Adsorbent of Anionic Dyes Removal from Aqueous Solution. Biointerface Resarch in Applied Chemistry 2021, 11, 13377-13401, doi:https://doi.org/10.33263/BRIAC115.1337713401.

60. Vijayaraghavan, K. Biosorption of lanthanide (praseodymium) using Ulva lactuca: Mechanistic study and application of two, three, four and five parameter isotherm models. Journal of Environment \& Biotechnology Research 2015, 1, 10-17. https://doi.org/10.1021/es9807744

61. Dehghani, M.H.; Dehghan, A.; Najafpoor, A. Removing Reactive Red 120 and 196 using chitosan/zeolite composite from aqueous solutions: Kinetics, isotherms, and process optimization. Journal of Industrial and Engineering Chemistry 2017, 51, 185-195, https://doi.org/10.1016/j.jiec.2017.03.001.

62. Mandal, P.; Nath, K.K.; Saha, M. Efficient Blue Luminescent Graphene Quantum Dots and their Photocatalytic Ability Under Visible Light. Biointerface Res. Appl. Chem 2021, 11, 8171-8178, https://doi.org/10.33263/BRIAC111.81718178.

63. Abdelhamid, H.N. Biointerface between ZIF-8 and biomolecules and their applications. Biointerface Res. Appl. Chem. 2021, 11, 8283-8297, https://doi.org/10.33263/BRIAC111.82838297.

64. Hassan, N.; Shahat, A.; El-Didamony, A.; El-Desouky, M.G.; El-Bindary, A.A. Synthesis and characterization of $\mathrm{ZnO}$ nanoparticles via zeolitic imidazolate framework-8 and its application for removal of dyes. J. Mol. Struct. 2020, 1210, 128029. https://doi.org/10.1016/j.molstruc.2020.128029. 